\title{
An Investigation on The Role of In-between Spaces in Iranian Traditional Houses as an Architectural Heritage: The Case of Kashan Houses
}

Abbas Havashemi ( $\square$ nb2723744@gmail.com )

KIAU: Karaj Islamic Azad University

\section{Mina Peysokhan}

Abacus Institute of Higher studies

Behnaz Aminnayeri

Islamic Azad University

Siamak Oanahi

Islamic Azad University

Research article

Keywords: in-between spaces, traditional houses structure, Kashan city, Iran

Posted Date: September 7th, 2021

DOl: https://doi.org/10.21203/rs.3.rs-837972/v1

License: (c) (i) This work is licensed under a Creative Commons Attribution 4.0 International License.

Read Full License 


\section{Abstract}

In-between spaces have the duty of separating other space by putting a distance between them, facilitating spatial identification and specification along with creating consequent spaces which gradually lead passers from public environment to more private sections. Designing such spaces was considered a necessity with significant importance in the architecture of Iranian Traditional Housing. Therefore, regarding the importance of the issue under study, the goal is to discover strategies applied in Iranian Traditional Houses by benefiting from the data gathered through a survey carried out on 50 respondents and technicians in the field of Iranian Traditional Architecture. To do so, EFA was utilized to specify factors creating by in between spaces in traditional houses. The result revealed that elements of continuity, hierarchy and spatial organization are the most evident factors in the architect of Iranian Traditional Houses and as the statistic showed that the highest level variance belonged to spatial organization.

\section{Introduction}

The last years at 19th century brought about changes in human modern lifestyle due to universal developments in various aspects of life (Inglehart 1997; Hesari et al., 2018; Norouzizadeh et al., 2021). Forming physical configuration were altered to suit new social, cultural encountered drastic changes in this era as well (Gottdiener 1995). Traditional architecture, the offspring of long-lasting challenge between the Iranians and the harsh environmental situation, encompasses a series of humanistic which from a homogeneous system with a specific physical identity (Kasma 2003). It is endowed with a unique functional nature which responds to the human needs and expectations, their activities and productive elements and environmental setting, reflecting spatial multi-functionality and connectivity (Razjoian 2009). Iranian architects had been aware of special techniques to benefit from ceiling, floor and wall and to separate a certain spatial unit based on the climate and culture of users (Balilan 2001; Kasmai 2003; Ahmadi 2012; Ghafourian et al., 2017a; 2017b).

Changes were also evident in the architecture of buildings, housing in specific, one of which was to eliminate successive spacing by in-between spaces built in accordance with Iranian culture (Balilan 2001; Ahmadi 2012). In modern Iranian architecture, such spaces have faded away, resulting in the loss of private zones, enhancing dominance of neighboring spaces and in some cases excessive extroversion not in line with Iranian culture (Norouzi 1999; Bulilan 2001).

In fact, in-between spaces are realized as interface spaces (Nooraddin 1998, 2002) affecting spatial configuration of architectural and urban complexes in the past which play substantial role in creating spatial link among elements sharing similar identity, the removal of which would lead to gradual demolition of boundaries either in the field of social relationships or structural foundation. Moreover, these spaces count for organizing the components and elements of architecture and urban spaces Parsaee et al., 2014). Different studies, have defined the term as a spatial setting for bilateral functions, or as the moment of charge from one space to another or connection/disconnection of outer/inner 
spaces (Anderson 1991; Gehl 1996; Hajer and Reijndorp 2001; Hillier and Hanson 1984; Skjaeveland and Garling 1997; Stevens 2007; Dovey and Polakit 2007).

Connection or disconnection of two spaces requires a third (mediating) space (Oldenburg 1999) known also as articulation (Rezakhani, 2013). According to terminology, understanding spatial features of inbetween space which requires words or terms reflecting multiple aspects of form, meaning and relevance of the space is the tool to impose changes in in-between space (Rezakhani 2013; Balilan 2011). Grutter (1987) calls for this mediating space in order to recognize an object. Articulation does not merely mean connection, but it has the ability to discipline the overall architecture (Hojat \& Nadimi 1981).

Studies conducted so far in Iranian setting have focused on documentation of traditional housing in different parts of country. Research projects on "in-between spaces" are either discussing the issue in urban scale e.g. (Ahmadi 2001). Or fundamental studies on the concept of between-ness (Noroozi 2013; Ahmadi 2012; Bemanian 2015).

According, the present study aims at specifying the role of in-between spaces in organizing and creating spatial link among architectural elements of traditional Iranian houses. Thus, implementing and inductive approach, through a descriptive-analytical method.

Today, due to limited architectural space and especially reduced size of contemporary habitation compared to traditional houses in the past, in-between spaces do not emerge in form of a specific structure or micro-space. So, the present study tends to fill in the existing gap in this regard.

The present study concentrates to find principle create by in-between spaces in the Iranian traditional houses. It is realized that in-between spaces have always played the role of a boundary line for identification and sacredness to certain places while they were built. Finally, special communication features of gain space determines theoretical framework of in-between spaces in accordance with main example of Iranian architecture.

\section{Literature Review}

\subsection{Definition and concept of in-between spaces}

Different researchers and scholars have proposed various definition and dimensions fir the term "inbetween spaces" Over the years.

In technical architectural dictionary it is defined as " A dynamic, moving space (Grosz 2001). A space within itself (Hillier 1996). A boundary built in sideline, vague hybrid, underestimated, unknown (Anderson 1991; Gehl 1996; Hajer and Reijndorp 2001; Hillier and Hanson 1984; Skjaeveland and Garling 1997; Stevens 2007; Dovey and Polakit 2007). It is not necessarily empty, vacant or remaining space (Gehl 2001). According to geometrical dimensions of a space counting in-between section, it turns into a stable Inhaled and exhaled by geometry, a location for simultaneous conditions (Nooraddin 1998, 2002). 
Therefore, in-between spaces do not separate, but they connect spaces. (The Metapolis Dictionary of Advanced Architecture, 2005)

The term "in-between" is synonymous to connection, continuity (distance, separation, border, limit, edge, chamber and threshold). From another point view, it is defined as the third or mediatory space (Grosz 2001). Either connection or disconnection of neighboring spaces require a third space to appear (Oldenburg 1999). In an architecture-based setting Such words are meaningful whenever the true existing spaces are homogeneous. As a result, the issue of recognizing distinct border between spaces is discussed, since architectural spatial zones are defined by distinguishing and differentiating them (Tschumi 1975). The boundaries between objects or even spaces identify structural and meaning-based characteristics of each, as well as their communication features.

Division between internal and external spaces dates back to the time when human built shelter for the first time. The significant difference between these two spaces is clarified when human beings brought their outdoor activities inside by developing novel patterns for their various activities (Nooraddin 1996). The link between internal and external spaces has obsessed with preserving the ties between nature and society simultaneously. On the other hand, every fronting shelter unit creates setting for different activities as well as a location for gatherings. In fact, this relationship is inevitable since any function of the enclosed space would be impossible without such a link (Nooraddin 1996). This, in-between space acts as a location for the confrontation of interior and exterior functions (Balilan 2011). Concerning the distinction of interior and exterior Bollnow maintains that "Such dichotomy between inside and outside is the basis for spatial perception and it can be considered as the key during the whole life (Grutter 1987).

The space bordering two objects (in-between space) is not hollow (Luz 2004). It is essential for specifying the objects. Without such spaces it is not possible to identify objects distinctly become of the significations role that they play in creating tics between single elements of space with other spatial segments (Grutter 1987).

\section{Research Context}

\subsection{Identification of the case studies}

In order to investigate in-between strategy, cases including similar climate and culture features were needed. Three houses were considered in this study, all of which located in Kashan in Iranian Central Plateau (Fig. 1).

Kashan is a city located in western fringe of central desert of Iran, a historical city dating back to prehistoric era. Figure 1 illustrates city map. Despite its historical background, Kashan mostly owns architectural historic heritage of only recent centuries because of various natural disasters and earthquakes which have brought about significant debris. Thus, the houses investigated in the present study belong to the Kajar/Qajar dynasty time which have remained almost unchanged, preserving initial plan and design. Houses selected for this purpose include: Tabatabaiha, Brujerdiha and Sharifian houses. 
Geometric models, Plans, locations, orientations, and prevailing wind of the city they are located in, are presented in figures (2-4).

\subsection{Brujerdiha House}

Brujerdi House dates back to 1900 to 1912, according to the inscriptions on four sides of hall. In fact, it is in form of backhouse and forecourt. The forecourt has a long yard with two major space collections on two ends which are higher compared with other parts (HajiGhasemi 1996).

\subsection{Sharifian House}

Built in 1852, the house is an important one in the area. The building is composed of three spatial complexes with two important ones in two floors on northern and southern direction (HajiGhasemi 1996).

\subsection{Tabatabaiha House}

The house was built in 1872. It is in fact two independent houses connected in a fine way which can be considered as backhouse and forecourt. Larger part of house has a rectangular yard with small bevels on four corners. The most important spatial part of the house is on southeast side higher than other parts of the building (HajiGhasemi 1996).

\subsection{In-between spaces in Iranian Traditional Houses}

An array of previous researches (Noroozi 2013; Ahmadi 2012; Bemanian 2015) considered three spaces of Iranian Traditional Houses as key elements of in-between places including Vestibule, Yard and Veranda.

\subsection{Vestibule}

Vestibule is the entrance space of each houses- just after entrance door- and the outer part of old houses built in different forms such as square, rectangle or octagonal. The vestibule was a division of entrance path into two or more directions and preserving part of boundary (Fig. 5) (Architecture\& Urbanism Encyclopedia, 2005).

\subsection{Yard}

In Iran, the form was widely used from ancient times (buildings with enclosed yard in the ancient city of Ur date back to four thousand years ago) for buildings with various functions. Building with enclosed yards in Iranian Central Plateau are introvert with little relationship with outside world (Ghobadian 2004). As it shown in (Fig. 6) the most common way of entering the yards was through vestibule.

\subsection{Veranda}

As an important space in Persian architecture, there could be found variety of verandas in terms of form, dimensions and location with a lot of functions. Veranda was usually open from one side as Fig. 7\&8 pictured (Mahmoodi 2005). It is a semi-open space formed around enclosed yard usually higher level than the yard (Memarian 2006). A space between yard and rooms (Ardalan 2001). A mediate space, the 
mediating feature of which was completely evident in its dual form in terms of shape (closed from three sides) (Mahmoodi 2005). Regarding the view into the building, veranda was usually higher than other parts of front (Memarian 2006).

\section{Methodology}

Data was collected by descriptive and phenomenological methods with historical- documentary approach and using related references and texts. The reference included Persian and English textbooks such as dictionaries, books, specialized magazines, theses and cases existing in Persian architecture. The analysis of data and findings from simulative studies are based on contrastive case to case studying. And finally, data analysis was carried out through data analysis by an inductive method based on a case to theory model.

The present study is an attempt to evaluate factors affected by the formation of in-between spaces. To do so, a survey was conducted using questioners to achieve authentic data. The respondents were characterized as having at least 5 years of experience teaching architecture-oriented topics at university level, so that they would have enough knowledge and information relevant to the subject of this study. The researchers decided to benefit from the viewpoints and ideas of scholars and university lectures based on 2 reasons: as technical analysis of architecture-oriented topics and concepts is an academic issue which requires professional opinion. Thus, common respondents would not be helpful in this regard.

By since the houses investigated in this study were un-occupied and have been re-utilized as museums, it was now possible to ask settlers or dwellers to attend the survey.

\subsection{Data collection}

The questionnaires were delivered to the respondents by two students from may 5, 2016 to july 11, 2016. Since the respondents were university lectures. Cornbach's and $\mathrm{KMO}$ were calculated to determine validity and reliability of questionnaires. From among the collected questionnaires, 50 were selected which contained answers to all items. Them they were analyzed and assessed.

\subsection{Measures}

Since the approach employs in the present study is explore-oriented, to find items related to the inbetween concept: First, regarding to explore items which were created by in-between spaces in Iranian Traditional House, we intended to use historical- documentary approach by using related references about traditional housing in Persian architecture of Kashan city. Second, the present researchers extracted 5 factors which were declined to 3 after consulting with academics and historians. These factors include Continuity, Hierarchy, Spatial organization. Then, we extracted 13 items, for measuring sub-constructs of Spatial organization (6 items), Hierarchy (4 items) and Continuity (3 items) which were derived from Ching )1979), T.Hall (1990), Lang (1987) and Meiss (1990) 
5-grade Likert scale for closed items was utilized. The items were arranged on a basis varying from "completely agree" to completely disagree ". Next, the data obtained were analyzed according to SPSS. ver.22 software.

\subsection{Sample}

The present study deals with identifying the constituent variables influencing formation of in-between spaces. In this method, variables are considered within factors in a manner that the value of variance reduces from each factor to its next-coming one; i.e., the variables accruing earlier and coming initially are more influential.

\section{Result}

\subsection{Factor Analysis}

Factor Analysis is a multi-faceted teaching for analyzing data, essentially used to drive a series of supposedly un correlated items which are them labelled as factors describing the observed variance in the initial set of data (Everitt and Dun 1991). Two major types of factor Analysis are considered as: confirmatory and explanatory analysis.

In the present study, empirical data were analyzed to explore and identify indices and the ties between them. The factors involved in creating in between space include: hierarchy, continuity and spatial organization, which were recognized after examination. The index for Cronbach's Alpha and is a means of measuring the level of uni-dimensionality of ideas, attitudes and opinions; i.e., the researchers tend to see to what extent the respondents have interpreted and realized the questions similarly. The index is basically rooted in measures and scales. Scales are a set of numbers allocated to persons, things or behaviors on a continuum in order to numerize qualities (Allen and Yen 2002).

As illustrated in Table 1, the value of Cronbach's Alpha and in the present study is equal to 0.864 which is regarded as significant reliability. Subsequently, to identify appropriateness of the ranges selected for the factors indicated in the questionnaire two tests were conducted:

The Bartlett's sphericity test and Kaiser- Meyer- Olkin (KMO)

Measure for specifying sample size.

The value of this index in our study is 0.673 as shown in Table 1 , which is an acceptable value.

To extract factors according to shared variance value, variables having higher levels of correlation are grouped together. Factors having Initial Eigenvalues of more than 1 are considered as significantly meaningful. As suggested by the Table 2, indicator 13 has got this characteristic.

Then, factors are derived which own higher percentages of variance. In cases which the value of variance is less than 50 percent. Variables with low shared level should be removed. As shown in Table 2, factor 
analysis conducted according to varimax rotation produced a factor-based structure containing 3 indicators, through 12 rotation patterns which is able to determine 63.673 percent of the variables. Under the column Rotation Sums of Squared Loadings, the total values of extracted factors after rotation are indicated. As can be inferred 3 factors have the potential of specifying variances. The sum of the squared factor loadings for each variable is termed "communality" referring to the proportion of each factor variance as accounted for by other involved variables. Focusing on communality in the Table 2, on can notice that the investigated variables define in-between spaces properly.

In general, from the questions and answers asserted in questionnaire we can conclude that factor 1 of "Spatial Organization" has the most recognizable impact on regarding certain spaces as in-between. With regard to factor analysis results. The first factor has the lion's share (24.887\% of the total variance) formation of in-between spaces which courts for highest factor loading and subsequently strongest effect. Other factors displayed following loadings:

- Spatial organization according to site conditions (culture) 0.777

- Spatial organization according to site conditions (climate) 0.724

- Spatial organization according to axial and central symmetry 0.707

- Spatial organization according to geometrical pattern 0.705

- Activity organization 0.626

- Territory organization 0.502

The second most effective factor is that of hierarchy which has acquired $22.218 \%$ of total variance. As illustrated in Table 2, the first and second factors together account for $47.105 \%$ of total variance.

The variable loadings for the second factor constituents were as follows:

- Difference in scaling 0.736

- Uniqueness of form 0.717

- Location with special identity 0.699

- Strategic positioning 0687

The third influential factor was detected to be "continuity" which includes $16.568 \%$ of total variance.

- Space without borderline 0.839

- Connection to the interior 0.725

- Experiencing the continuous phenomena 0.609

Had highest positive factor loadings respectively.

\section{Discussion}


By considering in-between spaces as a principal component of Iranian architecture, the present research attempted to benefit from Exploratory Factor Analysis (EFA) to seek for principles which lead to the creation of this function for spaces such as: vestibule, veranda and yard in Iranian houses. The authenticity indices. The reliability of the questionnaire was calculated through cronbach's as equal to 0.864 , which is satisfactory value. Moreover, in order to determine construct validity of the questionnaire, EFA methods were utilized. The results of KMO test produced value of 6730 which shows factors appropriate goodness of fit.

Since privacy and personal zone and territory have always been of great importance in Iranian architecture (Memarian 2006), designing separative and connective spaces such as vestibule, veranda and yard has been highly regarded by Iranian designers over years (Noroozi 2013; Ahmadi 2012).

The present study showed that the role and function of such spaces in Iranian architecture is more solely more than solely separating spaces. In fact, in-between spaces in Iranian architecture created spatial organization hierarchy and continuity (Ahmadi 2012; Aeinifar 2003).

As shown in Table 2, the most crucial role of in-between spaces was specified as spatial organization (24.887). The reason might be hidden in the importance of symmetric axis and spatial order in Iranian house plan (Memarian 2006; Pope 1965). As suggested by the studies in literature review, in-between elements of space in Iranian houses are organized in 6 manners which according to Ching (1979) represent spatial positioning of elements in a certain space or zone.

Culture and importance of private zone have decisive roles in organizing spaces (Ardalan 2001; Memarian 2006). Therefore, as reflected in the applied questionnaires, culture and climate are two substantial factors which a site imposes on the physique, while cultural and climate-oriented factors have led to the formation of introvert houses (Memarian 2006). Such introverted nature in the entrance is provided by vestibule as a filter followed by yard (see Fig. 9). Yard is considered the mediator between semi-private space (vestibule) and private zone of the house which is located in the center (completely private sections belonging to family members) (see Fig. 9). Whereas other spaces have been situated around that via a repeated rhythm. At the next level, these spaces have organized total houses space on specific axes in a relatively symmetric manner, creating an organized whole. Veranda and vestibule are located in the two extremes of the axis while the yard is placed in the center (see fig Fig. 10). positioning of in-between spaces on major axes (Aeinifar 2003) and from of such spaces creates a geometrical organization, which both causes observers attention to be attracted and the rules and regulations considered by the user to be provided, as asserted in Lang (1987). Therefore, it can be inferred that selecting types of components, connections between them and organizing them within the housing domain follows a kind of order and organization fundamentally, such geometrical order is manifested in from of an architectural work, present in its separate parts (Norberg-Shutlz 1980).

Edward T.Hall (1990) has mentioned activities and territory as affecting spatial organization. What T.Hall (1990) introduces as organization model is to use spaces with semi-fixed-features as a method of activity 
organization technique. These activities are supposed to be adapted to the users' culture. Vestibule, veranda and yard are such spaces (Aeinifar 2003).

Vestibule is both the entrance space and a location for gathering of strangers or gusts before being permitted to enter. It is also a place for dealing with those who do not tend to enter the house, or family private zone (Shah cheraghi 2011). This space is in accordance with Rappaport's (1977) definition of crowded spaces which are in charge of social controlling by giving the choice of selection and the possibility of interaction. Such functions are example of the role of vestibule (Hashti) in Iranian houses.

Yard (Hayat) is a place for living as well as a separative space. During hot spaces. It is appropriate choice for family living especially for houses located in hot arid climate. Veranda (Eyvan) is also a liveable place; a semi-open space connecting interior and exterior. The most appropriate definition for in-between spaces might be found in Humphry Osmond's; words who terms them "sociopetal spaces", as asserted in Hall (1990).

Therefore, according to previous studies, it can be claimed that all these 3 spaces have the potential of providing privacy for users (Ahmadi 2012; Memarian 2006) while privacy is an issue in accordance with existing pattern of activities, culture background, personal expectation and personality options. Thus, and space designed based on such principles, meets the three major needs of safety, identify and motivation (Pastalan 1970; Lang 1987; Altman 1975).

At the next level, the index for the factor of hierarchy was specified. In general, hierarchy encompasses primary and secondary elements (Meiss 1990). The elements creating hierarchy in an organized set are usually dominant ones (Meiss 1990). The difference is evident among forms, scales, spaces and visual systems, while the distinction is well recognized between the manner of using them compared to other parts. Such differences reflect the symbolic role of spaces in organizing the whole body (Ching 1979). As illustrated in Fig. 10, regarding size and form, those spaces differ from private zone situated around the yard in a linear order. Vestibule which usually has an 8-dimensional (Octa-gonal) shape in plans, is smaller than all other intermediate spaces, located to a corridor which facilitates limited visual contact to the yard. Located in the center of this symmetric organization is the yard which has acquired a broad rectangular shape with private zones forming around it. In fact, the connection between closed and open spaces and nature is supplied by the yard which plays the sociopetal role.

The third variable of hierarchy factor concentrates on different values corresponding to various spaces within a house. These values are determined by users' needs and desires as well as designer's choices; they might be based on personal preferences, cultural or team decisions (Ching 1979). In-between spaces have been placed in Iranian house plans both to have a symbolic function and to create aesthetic visual attraction via a hierarchical system among building parts. The most essential value created by these spaces is that of territory and proper definition of privacy. Organization among elements of between-ness in a house is seen through public areas which lead to semi-private spaces under certain hierarchical pattern, finally ending in private spaces of the housing; a taxonomy from public to private. In such house, 
private space does NOT begin in the entry threshold, rather special vivid rules of hierarchy and territory govern the formation of house structure (see Fig. 10 \& Table 3).

At last, continuity was specified as an influential factor on in-between spaces through index Z. Continuity or overlap between spatial elements leads to the reduction of significance by separate parts of the housing (Meiss 1990). According to Alexander (2002), active centers are formed and strengthened through bordering; a property which is well realized in traditional architecture, but missing in modern architecture. Alexander (2002) maintains that continuity in various elements of nature is responsible for the creation of functional characteristic and sustainability, in turn.

The necessity of involving spaces in housing plan without physical border which are characterized by visual and physical continuity, is evident in Iranian houses (Ahmadi 2012). Open/closed and semi-closed spaces are located next to each other connecting public and private zones (Norouzi 2012). Spaces playing the role of articulators attach others as mediators (Bemanian 2015).

Vestibule, veranda and yard have contacts with their previous and following spaces visually and physically, and this connection is continuous (Aeinifar 2003). In other words, the three spatial groups (open, close, semi-closed spaces) are not built in isolation or separately, rather each one is the continuation of another one, making each other meaningful. This continuity in combining spaces creates the feature of "expansion". For example, veranda is the expansion of rooms and rooms are the expansion of veranda. It is worth mentioning that no interruption or stop occurs and spatial dynamicity continues in spite of strict control of territories and values (Haeri 1995), (Balilan 2011). That is why presence in any of these spaces creates vision, view to the adjacent spaces which might need to be restricted to enhance privacy.

Another factor owned by continuous spaces in the feature of connecting interior and exterior (Kim, 2015), which is, in fact, the nature of in-between spaces (Nooraddin 1998, 2002) vestibule is located between the public space of outdoor (i.e, city) and private space of the housing which belongs to the household members (Aeinifar 2003). However, by entering vestibule, are does not enter the family's private zone. Guests or strangers, after which the mediating space of the yard is situated; a semi-private space used as living area in hot, arid regions. Veranda is a semi-open space, connecting open and close spaces and playing the role of a passing area closed spaces are in contact due to the presence of this semi-open space (see Fig. 11) (Haeri, 1995). From spatial point of view, in addition to the features mentioned, veranda creates spatial diversity, variety, cohesion and distinction as well as continuity between indoor and outdoor (Mahmoudi, 2005).

Yet another technique for creating continuity is to change transforming spaces into functional ones. In this case, a single spatial component can have two or more definitions simultaneously. A good example would be the gallery which I turned into a passage in Venturi's works, or Huller's entrance wall which could be a wall with a large opening or only two fiber glass columns (Mertins 2008). Such connections between spaces-even opposing ones-are linked (Ardalan 2001; Martins 2008). These spaces, in fact, encompass a part of the identity of both original spaces which connect them, what is the discussed as "experiencing 
the continuous phenomena" (Kim 2015). In-between spaces in Iranian houses not only put a distance between building elements or separation causes the manifestation of independent identify by any spatial element, whereas the same indication can create a unified, specific whole having unique, tight knit identity due to the attachment of parts (see Fig. 12) (Ahmadi 2012).

In Iranian traditional houses, along with daily and seasonal changes, different housing sections are adapted to the required functions. The yard adjusts spatial components and various activities, as well as organizing all the needed alterations to manage indoor activities. (Aeinifar 2003).

On the other hand, continuity of elements is made possible through connective constituents to create a single whole. Entrance space and rooms are connected through vestibule and rooms. Connective spaces not only facilitate passing but also they play the role of pause an short stay spaces as well (e.g veranda and yard). (Ahmadi 2012; Aeinifar 2003). As a part of interior, although that, it has no direct overview to the private or even semi-private spaces of the house.

\section{Conclusion}

According to what mentioned before, in-between spaces create personal, social, public and private spaces which determine boundary and territory between multiple spatial areas and provide a targeted discipline among different areas. In Persian traditional architecture, spaces known as in-between, held the responsibility of creating order and organizing for constituent elements of space. Accordingly, in-between elements -vestibule, yards and veranda- in a house are the agents of space continuity (see Table 4). The manner of linking these elements and the quality of their relationship creates space character and through this link, the form of relationship between spaces in various levels is sorted and combined. In all of these houses, due to their multi-function nature of in-between spaces, they are able to combine. As it shown in Table 4, in-between spaces result in continuity, hierarchy and spatial organization in Persian traditional architecture. These spaces also result in continuity of space fluidity creating an integrated unit.

In total, in-between space functions as a hidden but important key factor in presence or absence of crisis in current housing in Iran. In-between spaces in Iranian architecture hold the task of receiving, interpreting, modifying and changing data. The spaces indicate the level of privacy and function as a territory between multiple spaces, since respecting privacy is a factor of separation and distinction between phenomenon adjacent areas and it also refers to the manner of connection. Therefore, one major tasks of in-between spaces are control of territory and ownership and in-between space is the point where internal and external functions confront. Thus, manifestation of in-between space with its communicative features changes the differences existing in various sectors according to different proportions of space hierarchy and this happens through determination of communication pattern and the order dominating the relationship which results in space organizing.

The main problem in contemporary architecture of housing in Iran caused in the absence of in-between spaces (Ghafourian et al. 2016). As we have shown, in an array of houses, the only boundary between exterior and interior is a 'door' and interior spaces do not follow any principles like hierarchy or spatial 
organization. As a result, we face houses which are not adapted with Iranian culture since privacy and arrangement are considered as basic needs of habitants (Ghafourian et al. 2017).

\section{Abbreviations}

Here is the list of abbreviations we used in this article:

Kaiser- Meyer- Olkin: KMO

Exploratory Factor Analysis: EFA

\section{Declarations}

\section{Availability of data and materials}

The authors confirm that the data supporting the findings of this study are available on request from the corresponding author, Abbas Havashemi

\section{Author's Contributions}

Hereby, I as correspondent author consciously assure all persons who meet authorship criteria are listed as authors, and all authors certify that they have participated sufficiently in the work to take public responsibility for the content, including participation in the concept, design, analysis, writing, or revision of the manuscript.

\section{Acknowledgements}

This research was not supported by any Foundation, or Grant maker.

\section{Ethical Statement}

Hereby, I as correspondent author consciously assure that for our manuscript the following is fulfilled:

1) This material is the authors' own original work, which has not been previously published elsewhere.

2) The paper is not currently being considered for publication elsewhere.

3) The paper reflects the authors' own research and analysis in a truthful and complete manner.

4) The paper properly credits the meaningful contributions of co-authors and co-researchers.

5) The results are appropriately placed in the context of prior and existing research.

6) All sources used are properly disclosed. Literally copying of text must be indicated as such by using quotation marks and giving proper reference. 
7) All authors have been personally and actively involved in substantial work leading to the paper, and will take public responsibility for its content.

\section{Conflict of Interest}

We announce that there was not any fund from organizations or universities to do this research.

Date:08.01.2021

Corresponding author's signature: Abbas Havashemi

\section{Funding}

We announce that authors received no funding from any institution or university to write this paper.

\section{Competing Interest}

Authors announce that they had no Collaborations with advocacy groups relating to the content of the article. We also had no grants from an entity paid to the author or organization,

\section{References}

1. Alexander, C. (2002). The phenomenon of life: an essay on the art of building and the nature of the universe. Published by Center for Environmental Structure, United States (2004). ISBN 10: 0972652914.

2. Altman, I. (1975), Environment and social Behavior, Monterery, Ca: Brooks/ Cole.

3. Albaum, Gerald. (1997). The Likert scale revisited. Journal-Market research society, 39, 331-348.

4. Allen, M.J., \& Yen, W.M. (2002). Introduction to Measurement Theory: Waveland Press.

5. Anderson, S. (1991). On streets: Based on a project of the Institute for architecture and urban studies (4th ed.). Cambridge, Mass: MIT Press.

6. Ahmadi, F. (2012). Connection and disconnection in Persian traditional architecture: Kimiya-ye-Honar. Tehran: The Quarterly Periodical of the Advanced Research Institute of the Arts.

7. Aeinifar, A. (2003). The Pattern to Analyze Flexibility in Iranian Traditional Housing. Jornal of Fine Arts University of Tehran. ISSN 2228 6020. 21.

8. Ardalan, N. \& Bakhtiar, L (1973). The sense of unity: the Sufi tradition in Persian architecture. Isfehan: Press the Soil.

9. Balilan, L., Ittessam, E. \& Eslami, Gh. (2011). The role of in-between space in identification of spatial expanse of tissue: The identity of the city. Tehran: Islamic Azad University, Science and Research

10. Bollnow, O.F. (1963). Man and Space: book Human space. Hyphen Press (September 7, 2011).

11. Bemanian., M, \& Mirzaei, V, \& Saremi , H, \& Lilian, M. ( 2015). Expression of Spatial Continuity of Architecture and Urban Development within Iranian Bazaars (Case Study: Tabriz Bazaar). Ciência e 
Natura, Santa Maria, v. 37 Part 1 2015, p. 305-314.

12. Dovey, K. \& Polakit, K. (2007). Urban slippage: Smooth and striated streetscapes. In K. A. Franck \& Q. Stevens (Eds.), Loose space: Possibility and diversity in urban life. Abingdon: Routledge.

13. D.K.Ching, F (1979). Architecture: Form, Space, and Order. Wiley. ISBN: 0471286168.

14. Gottdiener, M. (1995). Postmodern Semiotics Material Culture and the Forms of Postmodern Life. Wiley-Blackwell.

15. Gehl, J. (1996). Life between buildings: Using public space. Arkitektens Forlag: Bogtrykkeriet.

16. Grosz, E. (2001). Architecture from the outside: Essays on virtual and real space. Cambridge, Mass: MIT Press. pp. 90-93

17. Grutter, Y. (1987). Ästhetik der Architektur: Grundlagen d. Architektur-Wahrnehmung. Berlin: Köln, Mainz Kohlhammer

18. Golpaiegani, A. (2004). Typology of garden houses of Bam. Department of Housing and Urbanism, Tehran.

19. Ghobadian, V. (1998) Climatic analysis of the Traditional Iranian buildings: Tehran: Tehran University press.

20. Ghafourian, M., Peysokhan, M., Hesari, E. (2017). Typology of Spatial Configuration and Hierarchy of Entry in Iranian Houses: Concentrating the Issue of Privacy. Physical Sacial Planning, 4(3), 129-144.

21. Ghafourian, M. Hesari, E. Peysokhan, M. (2017). Privacy in Traditional Houses of Bushehr. Qazvin: Jahad Daneshgahi Press.

22. Hajer, M., \& Reijndorp, A. (2001). In search of new public domain. Rotterdam: NAi Publishers.

23. Haeri, M. (1995). A research on use of architectural principles of traditional/ historic houses in modern architectural design, volumes 1 and 3, Department of Housing and Urbanism, Tehran.

24. Heidegger, M. (1971). Poetry, language, thought. New York: Harper \& Raw.

25. Hesari E., Peysokhan M., Havashemi A., Gheibi D., Ghafourian M., Bayat F. Analyzing the Dimensionality of Place Attachment and Its Relationship with Residential Satisfaction in New Cities: The Case of Sadra, Iran. Journal of Social Indicators Research 2019; 142(3): 1031-1053.

1. Hillier, B., \& Hanson, J. (1984). The social logic of space. Cambridge (Cambridgeshire), New York: Cambridge University Press.

2. Hillier, B. (1996). Space is the machine: A configurational theory of architecture. Cambridge: Cambridge University Press

3. Hillier, B. \& Hanson, J. (1984). The social Logic of Space, Cambridge: Cambridge University Press. 4. Hojat, M., \& Nadimi,H. (1981). Phd Thesis: Tehran University of Art.

\section{Inglehart, R .(1997), Modernization and Postmodernization: Cultural, Economic, and}




\section{Political Chance In 43 Societise(pp. 3-7). Prinction University Press. United Kingdom.}

6. Kaiser, H. F. (1960). The application of electronic computers to factor analysis. Educational and Psychological Measurement, 20, 141-151.

7. Kasmai, M. (2003). Climatic \& Architecture: Architecture \& Urbanism. Press The Soil.

8. Kateb, F. (2005). The architecture of Persian houses. Tehran: Ministry of Culture \& Islamic Guidance.

9. Kazemeini M, Ghafourian M, Hesari E. Recognizing Social Variables affecting on the sense of identity in the neighborhoods of Iranian - Islamic Cities- Case Study: Shanbedi Neighborhood, Bushehr. Iran University of Science \& Technology 2020; 8(1) :27-40. URL: http://jria.iust.ac.ir/article-11270-fa.html.

10. Kim, M. (2015). The Matters of the Continuity in Architecture. GSTF Journal of Engineering Technology (JET) Vol.3 No.3

11. Lang, J. (1987). Creating Architectural Theory: The Role of Behavioral Sciences in Environment Design. Van Nostrand Reinhold.

12. Luz, A. (2004), Places In-Between: The Transit(ional) Locations of Nomadic Narratives. Culture Nature Semiotics, Locations IV-Tartu, Estonia, 2004

13. Memarian, Gh. (2006). Persian house architecture: extrovert typology. Soroushdanesh press.

14. Mahmudi, A. (2005). A review on the importance of veranda and traditional houses: with special attention to Bam. Honar-Ha-Ye-Ziba. Journal of fine art: university of Tehran.

15. Mertins, D. (2008) Experience, Tectonics and Continuity. In Spuybroek,L. (2008) THE ARCHITECTURE OF CONTINUITY. V2_Publishing. (pp 12-30).

16. Norouzy, R. (2013). Study the concept of articulation in architecture organization: City and local architecture. Yazd University.

17. Norouzi, F (1999). The old city, Modern life: Monthly municipalities. Planning and Urban Management.

18. Nooraghaii, A. (2007). Typology of garden houses of Bam. Department of Housing and Urbanism, Tehran.

19. Nooraddin, H. (1996), A study of "in-between" spaces along streets as an urban concept in Islamic cities of the middle east with a case study in Cairo, Department of Town and Regional planning, Faculty of Architecture, Trondheim.

20. Nooraddin, H. (1998). 'Al-fina', in-between spaces as an urban design concept: Making public and private places along streets in Islamic cities of the Middle East. Urban Design International, 3, 6577.

21. .Nooraddin, H. (2002). In-between space: Towards establishing new methods in Street Design. Global Built Environment Review, 2, 50-57

22. Norberg-Shutlz, Ch. (1971). Existence, space \& architecture: Praeger Publishers. 
23. Norberg-shultz, Ch. (1965). Intention in Architecture. Cambridge: Massachuset. The MIT pres.

49. Norouzizadeh, Z., Bayat, F., Besharati Kivi, S., Rohani, A. R., Hamidi, R., Hamidi, N., Zare, N. Evaluation and comparative study of the components affecting the formation of a sense of belonging in the old and new context of Tabriz. Building Engineering and Housing Science 2021; 26.

1. Oldenburg, R. (1999). The great good place: Cafe's, coffee shops, bookstores, bars, hair salons, and other hangouts at the heart of a community. New York: Marlowe.

2. Parsi, F. (2003). Study the restoration issue of historical context. Tehran: Sahr.

3. Parsaee, M., Parva, M., \& Karimi, B. (2014). Space and place concepts analysis based on semiology approach in residential architecture. HBRC Journal. doi:10.1016/j. hbrcj.2014.07.001

4. Pastlan, LA. (1970). Privacy as a Behavioral Concept. Social Science. Vol. 45, No. 2 (APRIL 1970), pp. 93-97.

5. Pope, A.U. (1969). Introducing Persian architecture Asia Institute, Pahlavi University. ASIN: B001QNLXVA.

6. Von Mesiss, P. (1990). Elements of Architecture: From Form to Place. Routledge. ISBN13:9780419159407.

7. Shahcheraghi, A. (2011). Paradigm of Pardise, recognition \& re-creation of The Persian Garden.Tehran. ISBN: 978-600-133-017-9.

8. Razjouyan, M. (2009). COMFORT Design with Climate. hahid Beheshti University

9. Rappaport, A. (1977), Human Aspects of Urban Form, New York: Pergamon.

10. Rezakhani, Zh. (2013). An introduction to the concept of articulation in architecture based on Heideger etymology method: Journal of Iranian architecture. Tehran: Journal of Architecture and Urban Planning.

11. Sadr, A. (2005). Architecture\& Urbanism Encyclopedia: Iran, Mah-Honar.

12. Sadr, A. (1998). The philosophy of Architectural Space. Tehran: Biabani.

13. Saremi, A. \& Radmard,T (1997). Sustainable values in Persian architecture. Cultural Heritage Pubs, Tehran.

14. Stevens, Q. (2007). Betwixt and between: Building thresholds, liminality and public space. In K. A. Franck \& Q. Stevens (Eds.), Loose space: Possibility and diversity in urban life. Abingdon: Routledge.

15. Sultanzade, H. (1993). Entry spaces in the traditional architecture of Iran. Cultural \& Art Department of Tehran Municipal: Cultural research office.

16. T.Hall, E.(1990). The Hidden Dimension. Garden City. ISBN: 978038508476.

17. Tschumi, B. (1999). Preface. In Tschumi, B (Ed.), Le Fresnoy: Architecture In-Between (pp. 9-13). New York: The Monacelli Press.

18. Tschumi,B. (1975). The Architectural Paradox: Studio International. Revised in Tschumi, Architecture and Disjunction (1994).

19. Tavassoli, M. \& Bonyadi, N. (1990). Urban space design . 
20. http://anthropology.ir/node/19505

21. http://www.kashanica.com/

\section{Tables}

Table1. Reliability Statistics \& KMO and Bartlett's Test

Cronbach's Alpha Kaiser-Meyer-Olkin Measure of Sampling Adequacy. N of Items

$.864 \quad .673$

13

Due to technical limitations, Table 3 and 4 are only available as a download in the Supplemental Files section.

Figures 


\begin{tabular}{|c|c|c|}
\hline \multicolumn{3}{|c|}{ Table 2. Rotated Component Matrix \& total variance } \\
\hline & \multicolumn{2}{|c|}{ Rotation Sums of Squared Loadings } \\
\hline & $\%$ of Variance & Cumulative \% \\
\hline \multicolumn{3}{|l|}{.617} \\
\hline \multicolumn{3}{|l|}{.643} \\
\hline \multicolumn{3}{|l|}{.586} \\
\hline .665 & 24.887 & 24.887 \\
\hline \multicolumn{3}{|l|}{.415} \\
\hline \multicolumn{3}{|l|}{.472} \\
\hline \multicolumn{3}{|l|}{.638} \\
\hline .629 & 22.218 & 47.105 \\
\hline \multicolumn{3}{|l|}{.586} \\
\hline \multicolumn{3}{|l|}{.753} \\
\hline \multicolumn{3}{|l|}{.792} \\
\hline .758 & 16.568 & 63.673 \\
\hline \multicolumn{3}{|l|}{.724} \\
\hline \multicolumn{3}{|c|}{$\begin{array}{l}\text { Rotation Method: Varimax with Kaiser Normalization. } \\
\text { a. Rotation converged in } 12 \text { iterations. }\end{array}$} \\
\hline
\end{tabular}




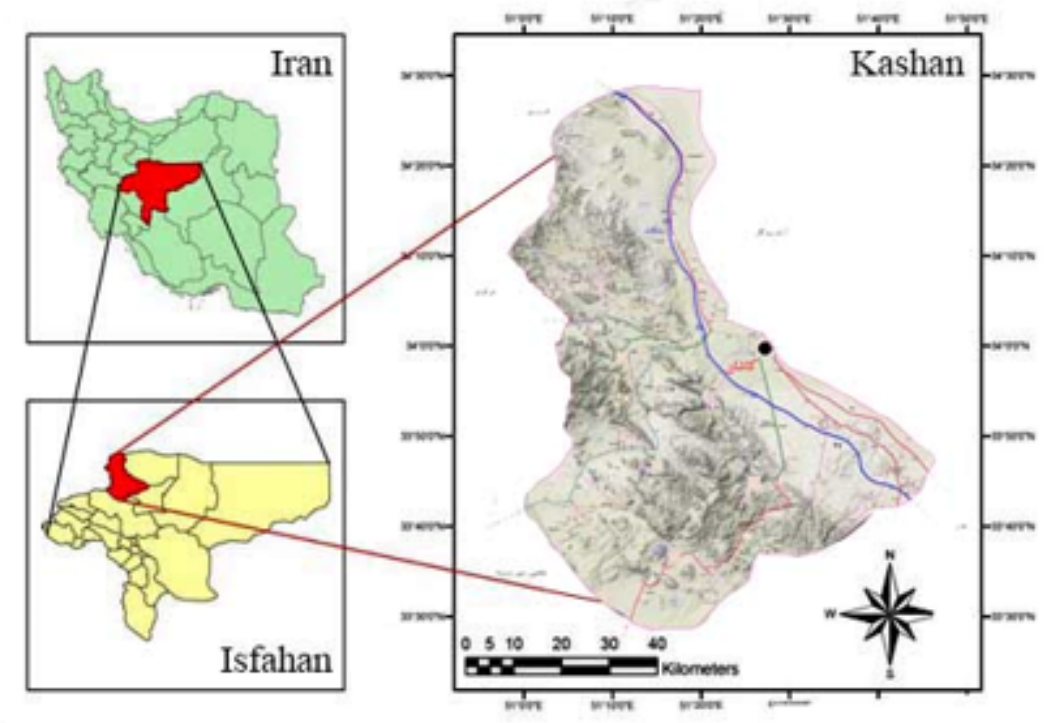

\section{Figure 1}

Location of the study area

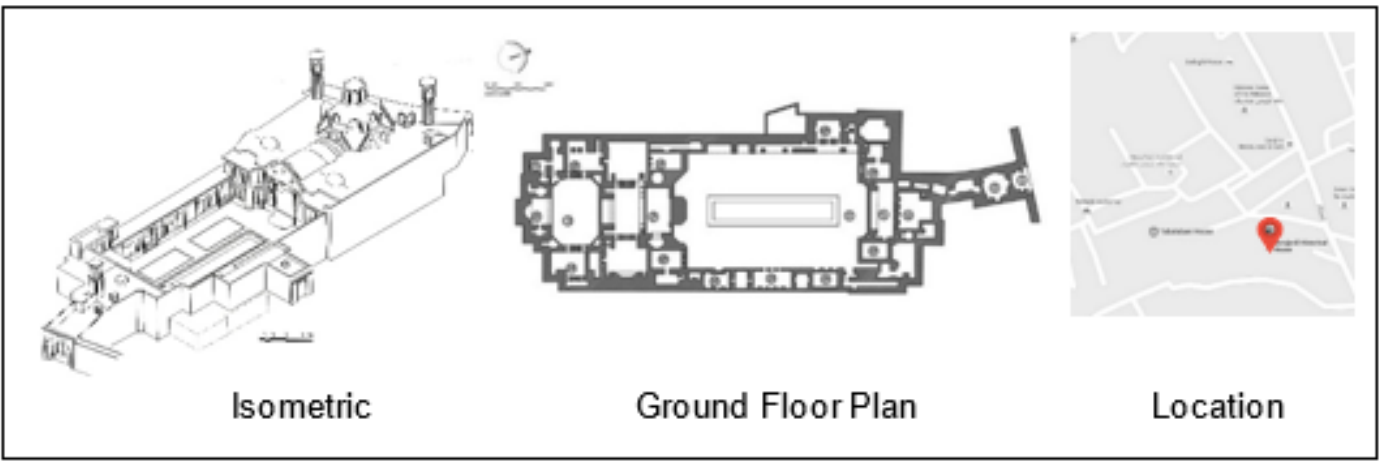

\section{Figure 2}

Isometric and location of Boroujerdiha House. Source: Authors based upon evidences in 2015 (HajiGhasemi, 1996).

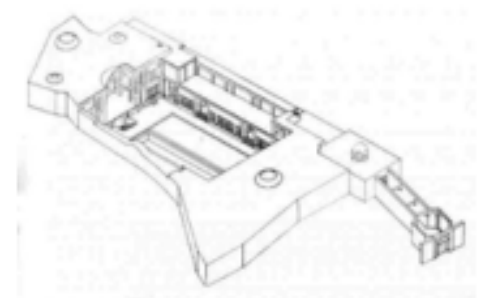

Isometric

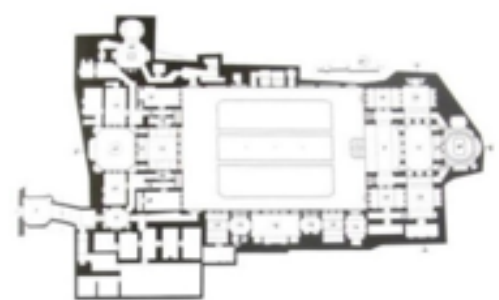

GroundFloor Plan

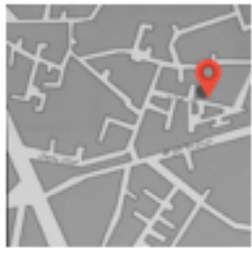

Location

\section{Figure 3}


Isometric and location of Sharifian House. Source: Authors based upon evidences in 2015 (HajiGhasemi, 1996).

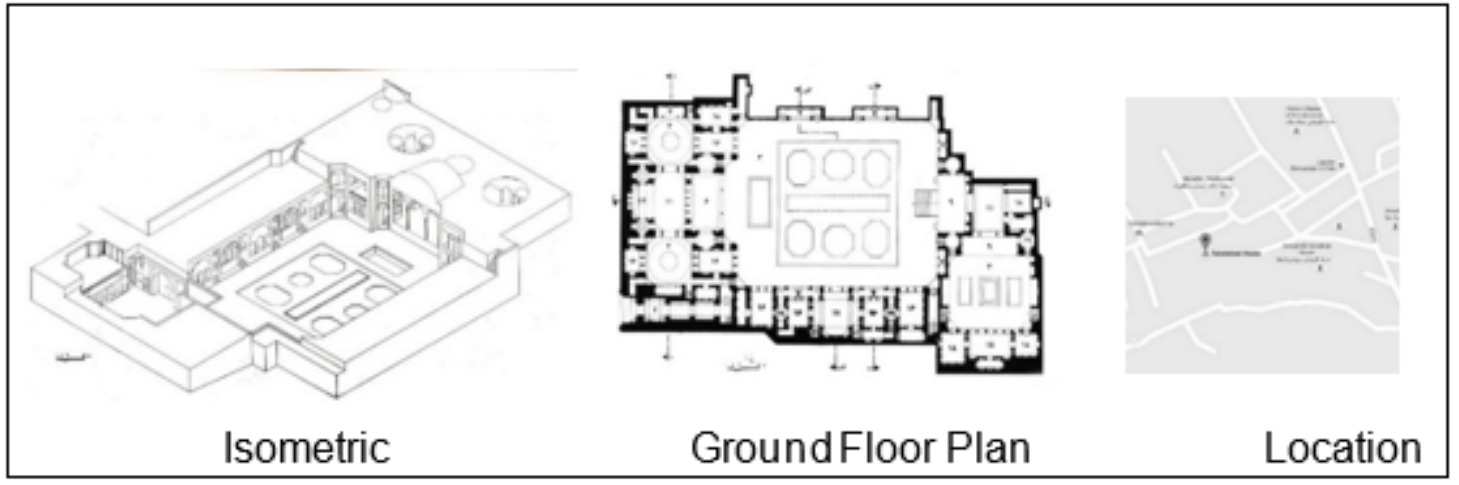

Figure 4

Isometric and location of Tabataeiha House. Source: Authors based upon evidences in 2015 (HajiGhasemi, 1996).

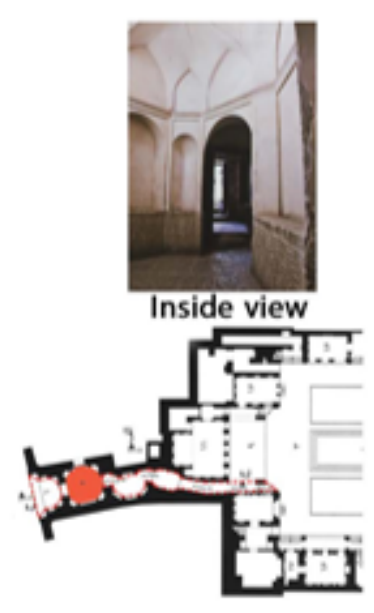

Boroujerdiha House

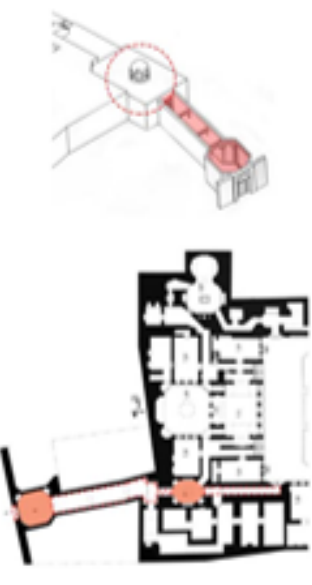

Sharifian House
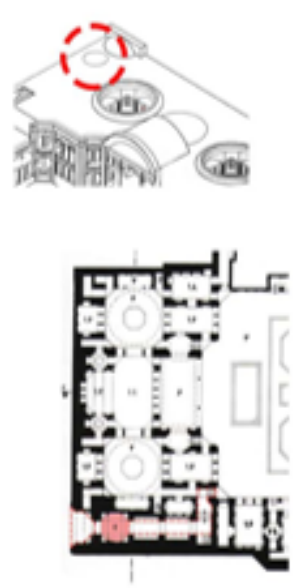

Tabatabiha House

\section{Figure 5}

Vestibule as a Mediating and transition from public and semi-public space to private space. Source: Authors based upon plans and Isometrics in 2015 (HajiGhasemi, 1996). 

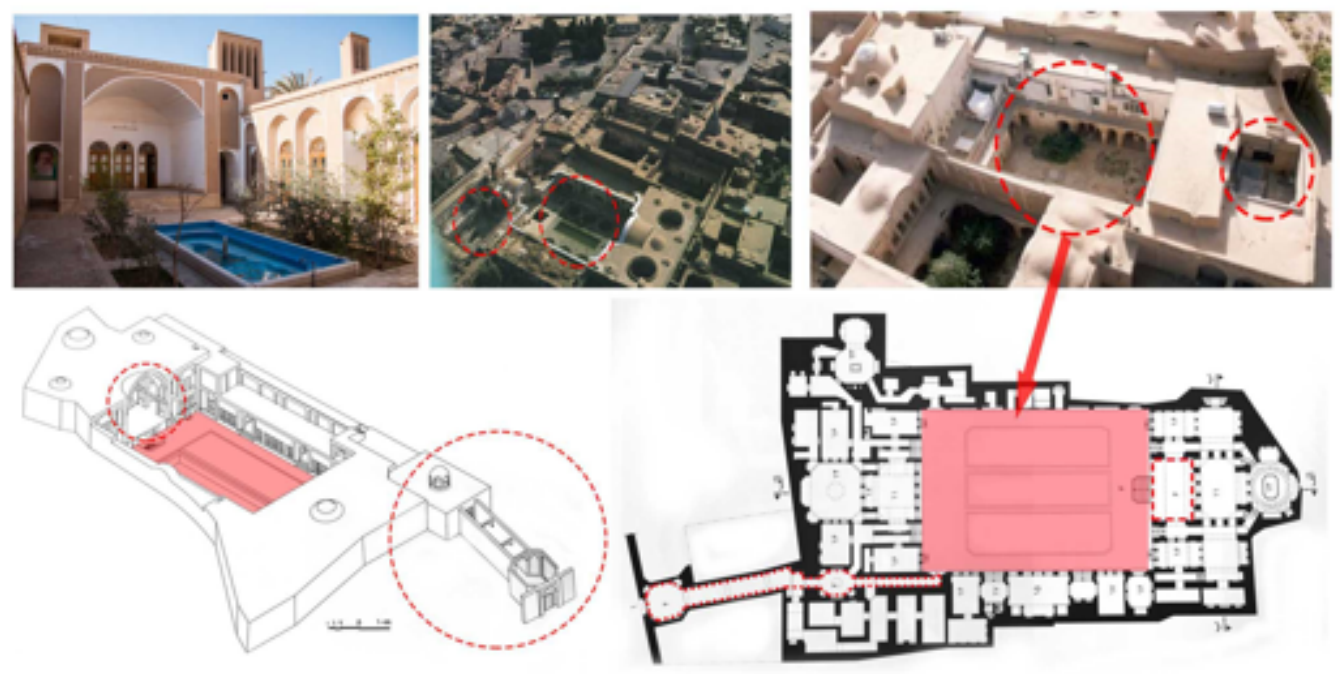

Figure 6

Pictures, plan and geometric models of yards. Source: Authors based upon evidences in 2015 (HajiGhasemi, 1996)
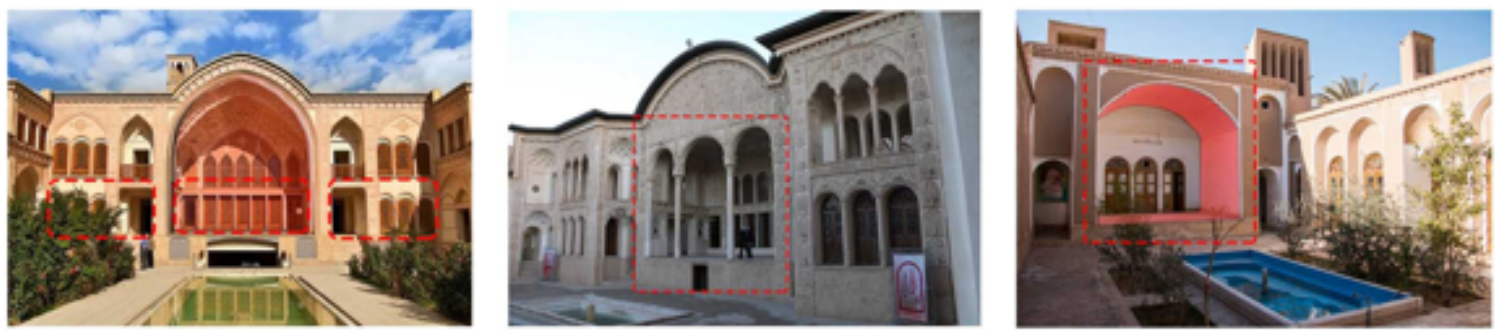

Figure 7

Example of veranda in vernacular residences. Source: Authors.

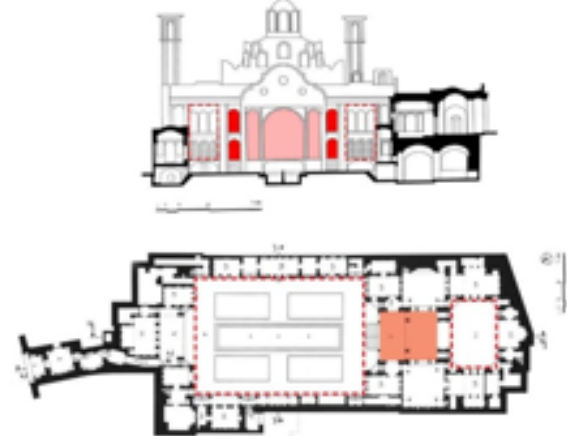

Boroujerdiha House
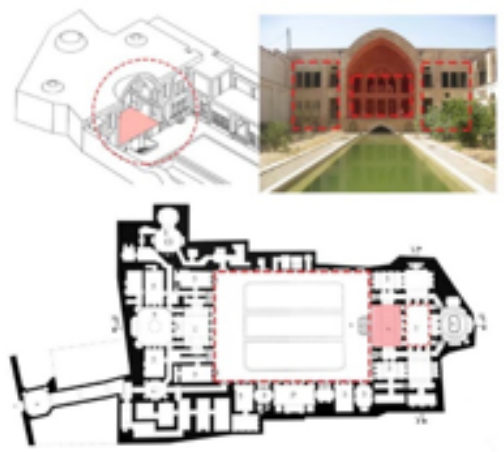

Sharifian House

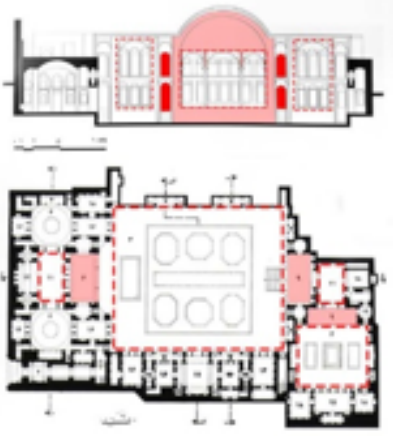

Tabatabiha House

Figure 8

Designing veranda as in-between space. Source: Authors based upon plans and Isometrics in 2015 (HajiGhasemi, 1996). 

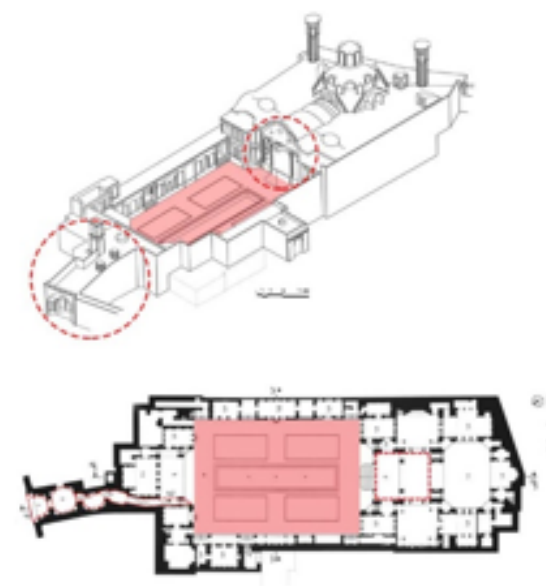

Boroujerdiha House
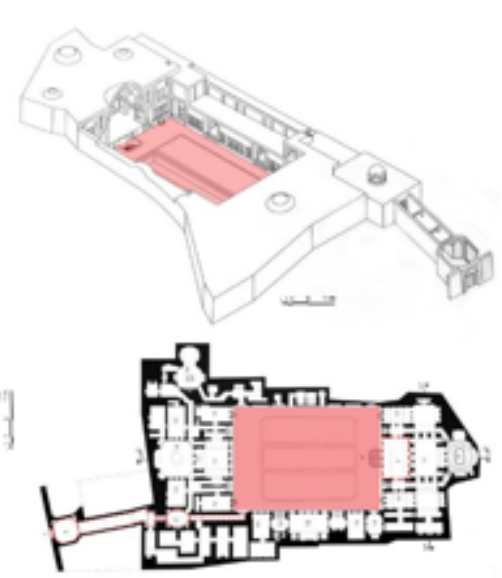

Sharifian House
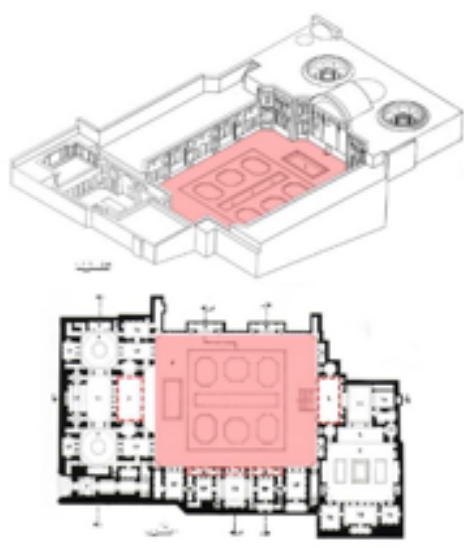

Tabatabiha House

Figure 9

Designing as in-between space. Source: Authors based upon plans and Isometrics in 2015 (HajiGhasemi, 1996).
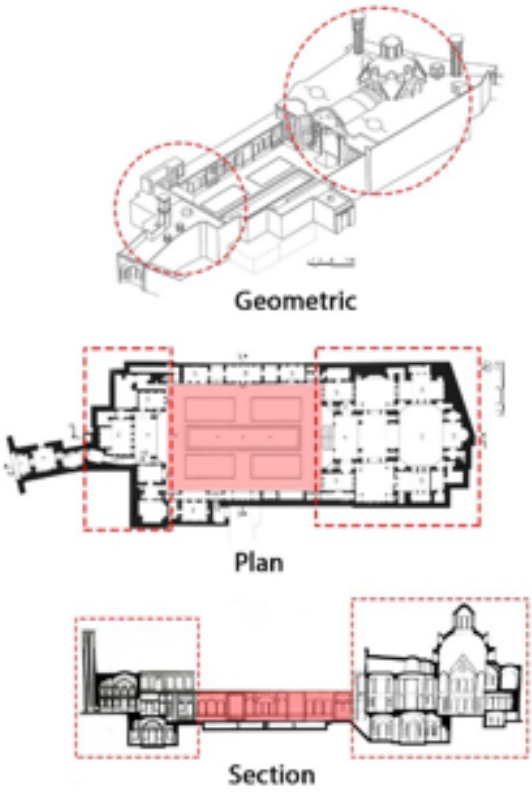

Boroujerdiha House

Lij private spade

inbetween space

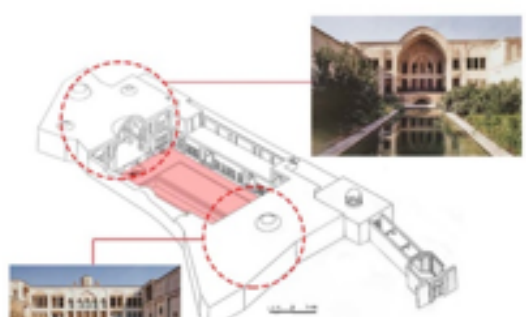

Geometric

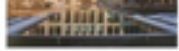

outside view

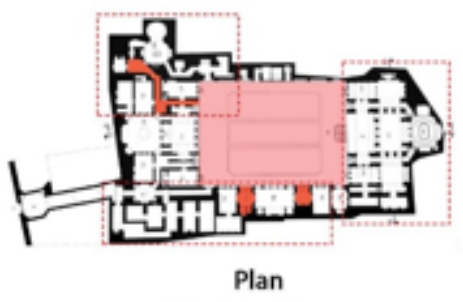

Sharifian House
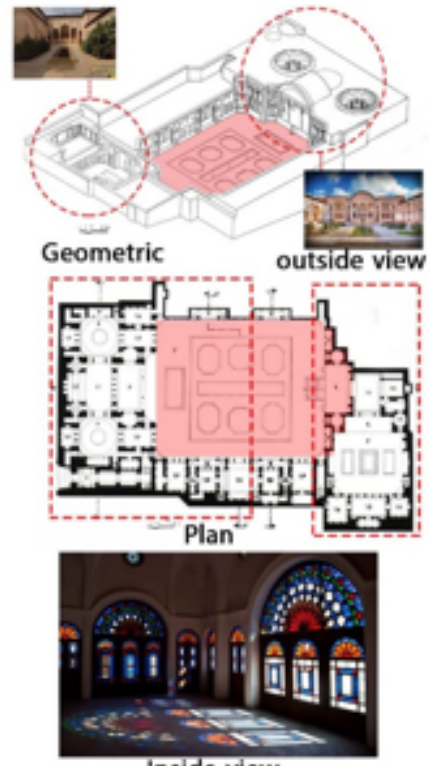

Inside view Tabatabiha House

\section{Figure 10}

Separation of public and private spaces. Source: Authors based upon plans, Isometrics and sections in 2015 (HajiGhasemi, 1996). 


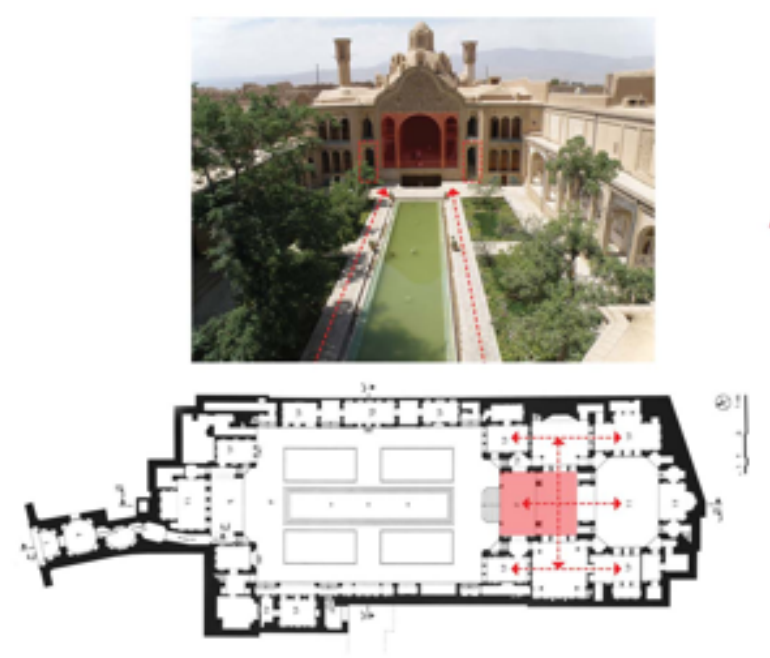

Boroujerdiha House plan
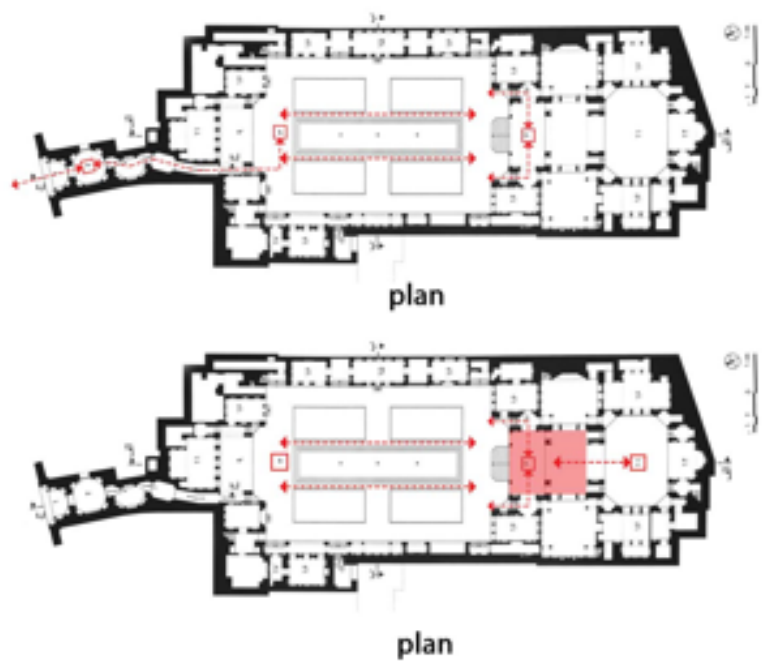

Figure 11

Continuity and combination of open, closed space. Source: Authors based upon plans in 2015 (HajiGhasemi, 1996).
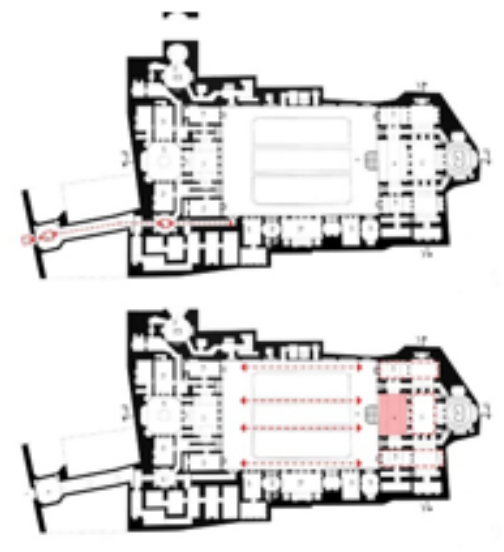
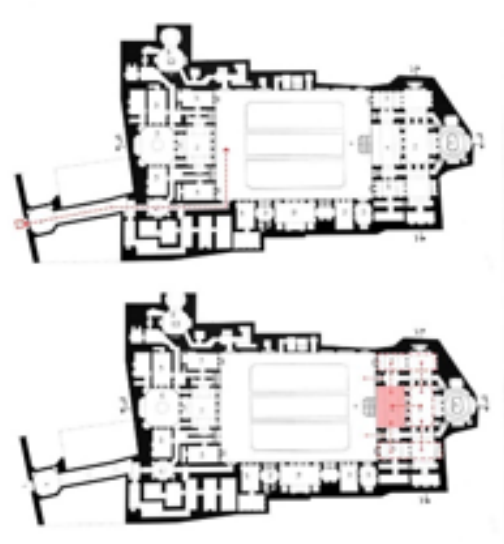
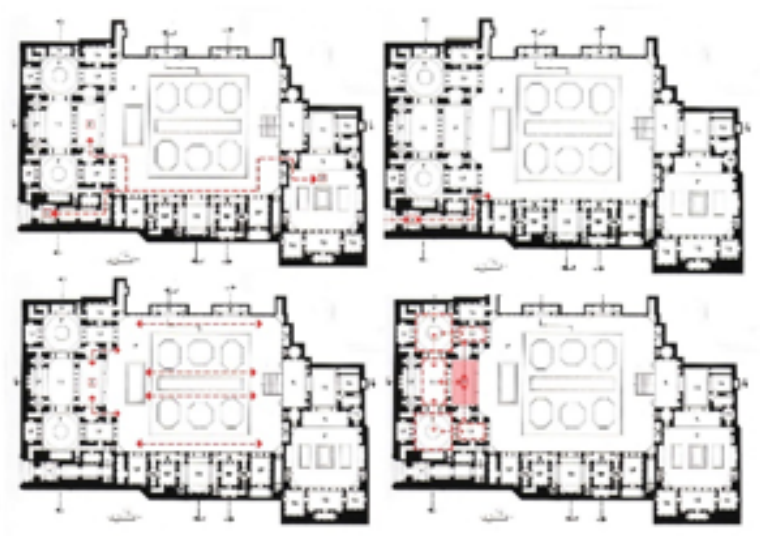

Figure 12

Continuity and combination of open, closed space. Source: Authors based upon plans in 2015 (HajiGhasemi, 1996).

\section{Supplementary Files}

This is a list of supplementary files associated with this preprint. Click to download.

- tables3and4.docx 